\title{
Um estudo de simulação computacional para a análise de perfis de aprendizagem organizacional
}

\author{
Debora Azevedo ${ }^{\mathrm{a}, *}$, Guilherme Luís Roehe Vaccaro ${ }^{\mathrm{b}}$, \\ Rodrigo Costa de Souza Lima ${ }^{c}$, Débora Oliveira da Silva ${ }^{\mathrm{d}}$ \\ a,*deboraazevedo@terra.com.br, UFRGS, Brasil \\ byuilhermev@unisinos.br, UNISINOS, Brasil \\ crodrigocslima@gmail.com, UNISINOS, Brasil \\ dosdebora@yahoo.com.br, UNISINOS, Brasil
}

\begin{abstract}
Resumo
Este artigo apresenta um modelo de simulação computacional que estende o modelo de aprendizagem mútua proposto por March (1991) com base no modelo SECl de Nonaka e Takeuchi (1997). Inicialmente são apresentadas considerações sobre aprendizagem organizacional e o modelo de aprendizagem mútua. Em seguida o modelo de March é revisitado, e são propostas extensões. São simulados diferentes cenários de evolução do modelo proposto, considerando as extensões, e analisados os resultados com base no referencial teórico. Finalmente, este trabalho apresenta considerações sobre a interpretação dos resultados obtidos em diferentes ambientes organizacionais, objetivando discutir a relação entre perfis de organização e aprendizagem organizacional.
\end{abstract}

Palavras-chave

Simulação. Aprendizagem organizacional. Modelos de aprendizagem.

\section{Introdução}

Há mais de três décadas discute-se a necessidade de as organizações aprenderem, sendo a aprendizagem vista não apenas como fonte de vantagem competitiva para a sustentabilidade das organizações, mas também pré-requisito para a inovação em processos e produtos. Parte dessa ênfase está baseada na premissa de que as empresas continuamente necessitam mudar internamente e adaptar-se às mudanças que encontram em seu ambiente (LAHTEENMAKI; TOIVONEN; MATTILA, 2001). No entanto, o processo complexo que gera aprendizagem organizacional é influenciado por um grande número de variáveis, envolvendo relações dinâmicas dos indivíduos e da organização com os ambientes internos e externos (ZANGISKI; LIMA; COSTA, 2009). Assim, é compreensível a busca crescente por mais conhecimento acerca das condições em que se dá o aprendizado, bem como dos processos de aprendizagem organizacional e de mudança, como caminhos para ampliar as possibilidades e os efeitos da aprendizagem. Ou seja, em boa parte das pesquisas sobre o tema procura-se compreender que estruturas organizacionais, que políticas de gestão de pessoas, que cultura, que valores, que tipos de liderança, que competências, que aspectos, enfim, podem favorecer ou obstaculizar processos de aprendizagem (SOUZA, 2004).

A compreensão das organizações a partir da visão baseada em recursos (VBR) propõe a utilização dos recursos físicos, financeiros, organizacionais e humanos para criar vantagem competitiva (FLEURY, A. C. C.; FlEURY, M. T., 2004). A componente da aprendizagem organizacional opera, no contexto da VBR, como meio gerador de diversidade na forma de combinação dos diferentes ativos, competências e capacidades da organização. Conforme Fleury, A. C. C. e Fleury, M. T. (2004), tarefas similares podem ser realizadas de forma distinta e difícil de ser imitada, em função da combinação desses recursos. Essa proposta é confirmada por Harlow (2008), que afirma existir uma relação 
significante entre o nível de conhecimento tácito da organização e o desempenho das organizações em termos de inovação.

Desse modo, entende-se neste trabalho que a aprendizagem organizacional pode ser um meio para a obtenção de vantagens competitivas sustentáveis. Essa compreensão está vinculada à visão da organização como um sistema e da aprendizagem como um processo de criação, compartilhamento e uso de conhecimentos. Dessa forma, a experiência gerada, assimilada e, preferencialmente, compartilhada entre os participantes de uma organização pode ser convertida em competências por meio da análise de resultados e de informações recebidas dos ambientes interno e externo da organização, e fomentar a criação de conhecimentos voltados à sustentabilidade da organização.

Conforme Garvin (1998), a aprendizagem organizacional envolve aspectos técnicos e sociais. Resulta, pela combinação e inter-relação desses sistemas, em aprendizagem a respeito de práticas e crenças sobre o ambiente interno e externo, tanto para os indivíduos como para o sistema que constitui a organização. Em posição similar, Souza (2004) ressalta alguns pressupostos dos estudos sobre aprendizagem organizacional, sendo dois deles especialmente relevantes para o presente trabalho: (i) a aprendizagem organizacional é um fenômeno ao mesmo tempo individual e coletivo; e (ii) a aprendizagem organizacional está intrinsecamente relacionada à cultura das organizações. Assim, ao falar em aprendizagem não se consideram apenas os processos cognitivos e tampouco a aprendizagem técnica, mas incluem-se as questões culturais como normas, procedimentos e práticas adotados pelos indivíduos e pelas organizações.

No sentido de ampliar a compreensão dos processos de aprendizagem, ao longo do tempo, vários modelos teóricos foram propostos, como por exemplo os de Shrivastava (1983), Fiol e Lyles (1985), March (1991), Nonaka e Takeuchi (1997), e Crossan, Lane e White (1999). Esses modelos diferem nos níveis de análise abordados e no enfoque a partir do qual consideram os processos de aprendizagem. No presente artigo revisita-se e amplia-se o modelo apresentado por March (1991). Essa escolha baseia-se em alguns aspectos singulares desse modelo:

- Não apenas é um modelo teórico, mas também um modelo que permite simulação computacional. Ou seja, permite que se façam inferências sobre comportamentos e se analisem diferentes cenários a partir da metáfora da organização como um sistema que aprende;
- Não considera todo e qualquer processo de aprendizagem como positivo. Pelo contrário, o conhecimento de uma organização pode diminuir enquanto ela aprende com seus membros ou com o mercado a sua volta. A questão de que a aprendizagem nem sempre leva ao desenvolvimento desejado é muitas vezes negligenciada por modelos de aprendizagem, ainda que as organizações também aprendam maus hábitos e desenvolvam mitos (LAHTEENMAKI; TOIVONEN; MATTILA, 2001);

- É um modelo simples que pode ser reproduzido e alterado a partir de outros pontos de vista ou considerações;

- Esse modelo, chamado de "aprendizagem mútua", tornou-se referência no mundo acadêmico por discutir a relação da aprendizagem com dois possíveis caminhos para a mudança e o desenvolvimento: exploration e exploitation.

Neste artigo busca-se, a partir da recriação do modelo, aprofundar algumas das análises realizadas por March (1991), bem como incluir outros aspectos na discussão, com base em outro modelo teórico, conhecido como modelo SECl*, apresentado por Nonaka e Takeuchi (1997). Ressalta-se que será utilizada a denominação original dos elementos do modelo no texto ("indivíduos" e "organização"), mas que na concepção ora apresentada "indivíduos" podem representar pessoas ou empresas e "organização" pode significar uma empresa ou uma cadeia na qual exista necessidade de troca colaborativa de elementos para geração de valor.

0 artigo estrutura-se apresentando conceitos essenciais de aprendizagem e os conceitos de exploration e exploitation. Segue com a apresentação dos modelos de March (1991) e de Nonaka e Takeuchi (1997). A seguir apresenta as contribuições propostas à luz desse referencial. Da compreensão desses elementos, com base em um conjunto de experimentos de simulação computacional, discute a relação entre diferentes perfis de organização e diferentes perfis de aprendizagem organizacional.

\footnotetext{
* Ikujiro Nonaka e Hirotaka Takeuchi, em seu livro intitulado "Criação de Conhecimento na Empresa", publicado originalmente em inglês no ano de 1995, apresentam um modelo de conversão do conhecimento, conhecido mundialmente como Modelo SECl. A partir da diferenciação feita por Michael Polanyi entre conhecimento explícito e conhecimento tácito, e considerando a interação entre esses tipos de conhecimento, os autores propõem quatro modos de conversão do conhecimento: (1) de conhecimento tácito em conhecimento tácito, chamado de Socialização; (2) de conhecimento tácito em conhecimento explícito, chamado de Externalização; (3) de conhecimento explícito em conhecimento explícito, denominada Combinação e (4) de conhecimento explícito em conhecimento tácito, chamado de Internalização. São exatamente as iniciais dos quatro modos de conversão de conhecimento que dão nome ao modelo SECI. Para maiores detalhes, ver Nonaka e Takeuchi (1997).
} 


\section{Conhecimento e aprendizagem organizacional}

No presente trabalho, considera-se que aprendizagem e conhecimento são conceitos associados que se relacionam sistemicamente. 0 conhecimento pode ser entendido como o conjunto de crenças, esquemas e modelos mentais sobre os quais são geradas decisões. 0 conhecimento organizacional estabelece-se pelo compartilhamento e pela comunhão de tais crenças e modelos no âmbito de representação coletiva de uma organização (SANCHEZ; HEENE, 1997), provendo bases para a realização de ações.

Já a aprendizagem é o processo pelo qual o conhecimento é gerado (criado e recriado, apropriado, difundido). Nesse processo diferentes fontes de dados e informação são compreendidas e assimiladas, objetiva e subjetivamente, a partir de experiências individuais ou coletivas (NADLER; GERSTEIN; SHAW, 1992, COHEN; LEVINTHAL, 1990). Fleury, A. C. C. e Fleury, M. T. (2004) estabelecem que o processo de aprendizagem organizacional envolve compreensão das relações dinâmicas do contexto no qual a organização encontra-se inserida. Reforçando essa visão, Zanginski, Lima e Costa (2009) afirmam que a aprendizagem organizacional pode ser percebida na interpretação e entendimento dos processos de ação, reflexão e disseminação. Considerando que o conhecimento é um produto de origem intrínseca às pessoas da organização, os possíveis resultados de um processo de aprendizagem organizacional não estão no provimento de resultados de desempenho com ganhos diretos de competitividade ou resultados financeiros positivos, mas na interpretação dos resultados e na geração de conhecimentos e competências, mesmo em situações onde o resultado de desempenho foi negativo. A capacidade de criação de valor dos processos de aprendizagem reside principalmente nos saberes físicos-emocionais-atitudinais criados e compartilhados pelos indivíduos e em sua capacidade dinâmica de gerir esses saberes para criar vantagens competitivas sustentáveis (TEECE, 1998 apud HARLOW, 2008).

Porém, para que o enlace entre aprendizagem e conhecimento possa ser reforçado de forma positiva, ambientes e processos adequados precisam estar disponíveis. As estruturas organizacionais devem prover meios para fomentar a colaboração e o desenvolvimento da autonomia, e o contexto da organização proporcionar condições técnicas e políticas para o aprendizado. Em geral, esse tema é abordado na literatura pela identificação e tentativa de eliminação das barreiras à aprendizagem (ZANGISKI; LIMA; COSTA, 2009). Por barreiras à aprendizagem organizacional, Nadler, Gerstein e Shaw (1992) compreendem elementos associados à cultura da organização, e que estão baseados em seus valores e crenças. Barreiras podem ser explícitas ou tácitas, mas têm como efeito principal o impedimento do processo de formação de conhecimento e, mais amplamente, de competências. Esses autores citam, como principais barreiras:

- Falta de capacidade de refletir e interpretar, com potencial foco no agir pelo resultado, sem o adequado tempo de amadurecimento ou planejamento. Essa barreira pode impedir a busca por soluções alternativas às previamente conhecidas, a despeito de seu desempenho, podendo ser associada a certa rigidez em termos de processos e práticas, bem como da cultura, com ausência de espaços para a explicitação de diferenças entre as crenças individuais e as da organização;

- Falta de capacidade de disseminar o conhecimento, tipicamente associada à ausência de meios para o compartilhamento do conhecimento e das práticas entre indivíduos ou entre grupos, gerando-se ilhas de conhecimento;

- Falta de capacidade de agir, associada ao excesso de atribuições ou à falta de foco em termos de prioridades e de objetivos. Também pode estar associada ao excesso de controle sobre as ações individuais ou ao foco excessivo nos meios, em detrimento dos fins.

Ponderando essas barreiras, constata-se que é na construção coletiva e no constante tensionamento entre pensar-agir-refletir que se criam tanto as oportunidades como as barreiras à aprendizagem, pois é na dialética entre pensar e agir que se estabelecem as bases para o processo de criação de conhecimento (NONAKA; RYOKO, 2003). E é no processo dinâmico e interativo de análise, ação e síntese que se criam ciclos de transformação do conhecimento organizacional.

\section{Exploration e Exploitation como caminhos para a vantagem competitiva}

March (1991) apresenta um modelo estocástico para processos de aprendizagem em organizações que visa elucidar algumas das relações entre exploration (exploração no sentido de pesquisa) de novas possibilidades e exploitation (exploração no sentido de uso) de velhas certezas nas organizações. A questão abordada é como as organizações escolhem entre esses dois enfoques e como se pode melhorar o balanço entre eles. Para uma 
melhor compreensão das diferenças entre esses conceitos, apresentam-se algumas características de exploration e de exploitation no Quadro 1.

March (1991) relaciona os conceitos de exploration e exploitation com o processo de aquisição de conhecimento pelas organizações. 0 modelo apresentado por ele parte do conceito de "aprendizagem mútua" e busca explicar o trade-off existente entre exploration e exploitation, analisando a relação entre acumulação e utilização de conhecimento nas organizações. 0 conceito de “aprendizagem mútua” baseia-se na ideia de que as organizações acumulam conhecimento - na forma de procedimentos, normas, regras e formulários - aprendidos a partir dos seus membros, ao mesmo tempo em que os indivíduos em uma organização são socializados com as crenças dessa organização (MARCH, 1991). Pode-se conjecturar que organizações com menos barreiras em termos de reflexão e interpretação, no sentido atribuído por Nadler, Gerstein e Shaw (1992), tenham maior inclinação à exploration, enquanto organizações com maiores barreiras dessa natureza, ou em situações que não demandem novo conhecimento, terão maior inclinação à exploitation. No entanto, é coerente pensar que ambas as formas de aquisição de conhecimento estejam presentes em uma dada organização.

No presente artigo visa-se explorar um pouco mais o modelo de March (1991) - a partir de sua recriação - e ampliá-lo, acrescentando-lhe outras dimensões. Com isso buscam-se novas compreensões sobre o processo de aprendizagem a partir das interações dos indivíduos entre si e destes com a organização.

\section{Simulação computacional e a compreensão dos processos de aprendizagem nas organizações}

A simulação consiste na recriação de um sistema em um ambiente controlado, de modo que seja possivel compreender, manipular e verificar seu comportamento de forma segura e a custos relativamente menores (VACCARO, 1999; CASSEL; VACCARO, 2007); por esse motivo a simulação é geralmente aplicada em sistemas ou processos complexos. Mais especificamente, compreende-se por simulação uma metodologia experimental e aplicada que tem por objetivo usar modelos para (SHANNON, 1992):

- Descrever comportamento de sistemas;

- Construir teorias ou hipóteses a partir de comportamentos observados;

- Inferir comportamentos futuros, ou seja, efeitos produzidos por mudanças na estrutura ou no método de operação do sistema.

Ou seja, a simulação é uma ferramenta exploratória de apoio à decisão e, além do projeto de um modelo, compreende necessariamente a realização de experimentos que permitam a análise de comportamentos futuros, bem como possibilitem a construção de novos cenários a partir de alterações no sistema.

0 uso da simulação está incorporado a determinadas áreas, como análise de capacidade produtiva, análise de políticas de produção, análise de estratégias logísticas, alternativas de investimento, políticas de preços, estratégias de marketing, estudos de aquisição, análise de fluxo de caixa, análise preditiva etc. (SHANNON, 1992; PIDD, 1994). Entretanto, outras áreas, como os estudos em aprendizagem organizacional, utilizam-se pouco dessa ferramenta. Sob esse aspecto, o artigo de March (1991) destaca-se, pois parte de um modelo de simulação para compreender algumas perspectivas dos processos de aprendizagem organizacional.

0 processo de simulação parte do ser humano e de suas percepções (Figura 1). Diferentes pessoas podem ter diferentes percepções de um mesmo sistema, pois essas são fruto de reflexões a respeito do comportamento do sistema tangível (PIDD, 1994). Assim, o modelo apresentado neste

Quadro 1. Características de exploration e exploitation.

\begin{tabular}{|c|c|}
\hline Exploration & Exploitation \\
\hline $\begin{array}{c}\text { Pesquisa, variação, correr riscos, experimentação, } \\
\text { flexibilidade, descoberta, inovação; }\end{array}$ & $\begin{array}{c}\text { Refinamento, escolha, produção, eficiência, seleção, } \\
\text { implementação, execução; }\end{array}$ \\
\hline Pesquisa básica; & Desenvolvimento do produto; \\
\hline Preocupações com o longo prazo; & Preocupações com o curto prazo; \\
\hline Retornos incertos, a médio e a longo prazo; & Retornos mais certos, a curto e a médio prazo; \\
\hline Consequências demoram e podem ser vagas; e & Consequências percebidas rápida e precisamente; e \\
\hline Feedback demora, nem sempre ocorre e pode não ser claro. & Feedback rápido, claro, próximo. \\
\hline
\end{tabular}

Fonte: adaptado de March (1991). 


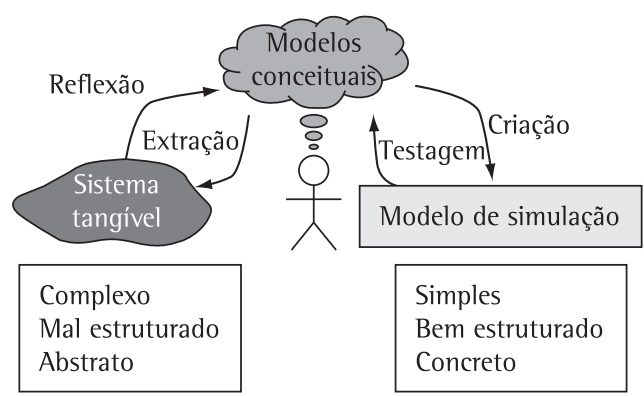

Figura 1. Relação entre modelos e realidade. Fonte: adaptado de Pidd (1994).

artigo não pretende abarcar uma totalidade de teorias ou pontos de vista sobre aprendizagem nas organizações, mas, baseado em alguns pressupostos, busca explorar o tema e contribuir com ideias e propostas teóricas.

\section{0 modelo de aprendizagem mútua de March}

0 modelo de aprendizagem mútua apresentado por March (1991) tem como principais características:

- A existência de uma realidade externa $m$-dimensional binária $(-1 ; 1)$, cujos valores têm iguais probabilidades de ocorrência e cujas dimensões são independentes;

- A consideração de crenças, dos indivíduos e da organização, por meio de um código de compreensão da realidade. Essas crenças assumem os valores $(-1 ; 0 ; 1)$, mimetizando discordância, indiferença ou concordância com cada dimensão da realidade previamente estabelecida; e

- Uma estrutura probabilística para os mecanismos de aprendizagem, na qual:

- os indivíduos têm uma probabilidade $p_{1}$ de modificarem suas crenças toda vez que a organização tem uma crença diferente e não neutra, em uma dimensão dada. Para March, $p_{1}$ representa a efetividade da socialização do indivíduo na organização;

- por outro lado, a organização aprende à medida que seu código tem uma probabilidade $p_{2, k}$ a se adaptar às crenças dos indivíduos de um grupo denominado "superior", ou seja, indivíduos cujas crenças correspondem à realidade em mais dimensões que as da organização. Nesse caso, $p_{2}$ indica a efetividade da organização em aprender; e k é um indicador para o percentual de indivíduos do grupo superior que diferem do código em cada dimensão.
No entanto, o modelo de March (1991) considera que as crenças de um indivíduo não influenciam diretamente as crenças de outros e que os efeitos da realidade são indiretos, ou seja, nem os indivíduos nem a organização experienciam diretamente a realidade. Conforme March (1991, p. 75),

[...] o processo começa com um código da organização que se caracteriza por crenças neutras em todas as dimensões e um conjunto de indivíduos com diferentes crenças que apresentam, em média, nenhum conhecimento. Ao longo do tempo, o código organizacional afeta as crenças dos indivíduos, ao mesmo tempo em que é afetado por essas crenças. As crenças dos indivíduos não afetam as crenças de outros indivíduos diretamente, mas apenas por afetarem o código da organização. Os efeitos da realidade são também indiretos. Nem os indivíduos nem a organização experienciam a realidade. A melhoria no conhecimento advém de o código imitar as crenças (incluindo as crenças falsas) de indivíduos superiores, e de os indivíduos imitarem o código (incluindo suas crenças falsas) [...].

A partir desse modelo, March (1991) gera uma série de cenários, os quais se iniciam com um posicionamento neutro em todas as dimensões do código da organização e um conjunto de indivíduos com variadas crenças que, na média, representam nenhum conhecimento.

\section{Considerações sobre o modelo de aprendizagem mútua}

Ao analisar o modelo originalmente proposto por March (1991), alguns pressupostos e características merecem atenção:

- 0 conhecimento de um indivíduo (ou da organização) é medido pelo número de dimensões em que suas crenças (ou o seu código) são idênticas à realidade;

- As análises apresentadas por March (1991) referem-se ao conhecimento adquirido pela organização ao longo do tempo (e não ao conhecimento dos indivíduos);

- A partir de um determinado momento, a relação entre o conhecimento da organização e o da média dos indivíduos atinge um equilíbrio estável, não havendo mais a possibilidade de aprendizado; e

- A manutenção do balanço exploration $\times$ exploitation ocorre enquanto esse equilíbrio não for alcançado, mas, em geral, na análise original foi estudada a situação após ter-se alcançado o equilíbrio.

Esta seção analisa uma recriação do modelo apresentado por March (1991), para fins de comparação com os resultados apresentados 
naquele modelo. 0 desenvolvimento apresentado nas seções seguintes contempla os três primeiros pressupostos citados anteriormente. Quanto ao quarto pressuposto, em alguns casos optou-se por avaliar uma situação anterior ao equilíbrio e uma posterior ao equilíbrio, por se considerar que nem sempre as organizações e o mercado teriam um tempo tão grande à disposição para adquirir conhecimento. 0 banco de dados dessa recriação foi desenvolvido no software Microsoft Access. 0 modelo foi implementado em Borland Delphi 6.0, e para a apresentação dos dados de saída optou-se por utilizar gráficos gerados no software Maple 11.0.

Para fins de comparação com o estudo original, foram conduzidos experimentos de simulação computacional e realizada a análise sucessiva e comparativa de cenários, buscando-se compreender os impactos da variação dos parâmetros do modelo sobre o percentual de conhecimento acumulado pela organização. Mantiveram-se os parâmetros originais de 30 dimensões da realidade, 50 indivíduos e 80 replicações do modelo. Cada replicação evolui em um horizonte temporal de 100 períodos. Os resultados foram testados ao nível de significância de 5\%, com testes paramétricos de comparação de médias. Também se mantiveram as mesmas denominações de parâmetros utilizadas por March (1991), a fim de facilitar a compreensão do modelo.

\subsection{Efeito das taxas de aprendizagem em um sistema fechado}

Segundo March (1991), um sistema fechado compreende um modelo que investiga apenas 0 ambiente interno da organização, sem considerar a existência ou a influência de fatores externos. Um dos aspectos estudados por March (1991) é a relação dos níveis de socialização $\left(p_{1}\right)$ com a velocidade de aprendizagem da organização $\left(p_{2}\right)$. E uma das conclusões apresentadas, a de que nem sempre um aprendizado rápido (por parte dos indivíduos) é desejável, já que um aprendizado mais lento permitiria maior exploração (exploration) de alternativas possíveis, e maior balanceamento no desenvolvimento de competências especializadas.

$\mathrm{Na}$ Figura 2 observa-se o percentual de aprendizagem (eixo vertical, indicado por perc) gerado na organização pelas variações de $p_{1}$ e $\mathrm{p}_{2}$, após o equilíbrio do sistema, na forma de uma superfície e de suas curvas de nível. Pode-se observar que o máximo de conhecimento é conseguido na região que combina uma probabilidade de socialização com o código da organização $\left(p_{1}\right)$ variando de 0,1 a 0,3 , com uma velocidade de aprendizagem organizacional $\left(p_{2}\right)$

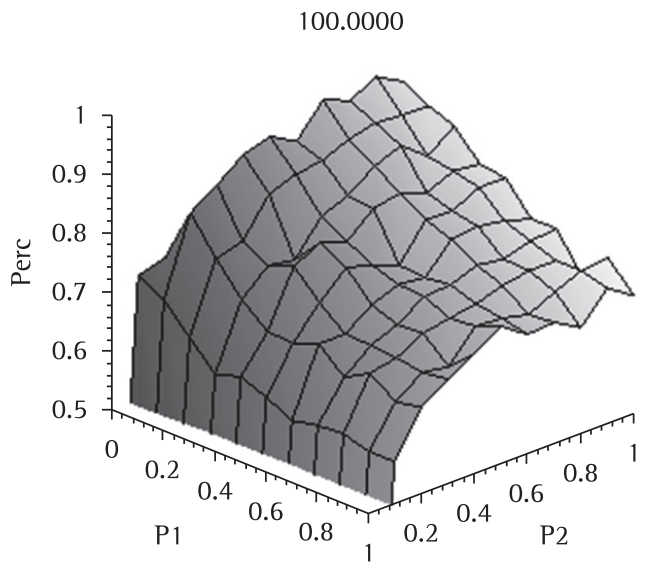

100.0000

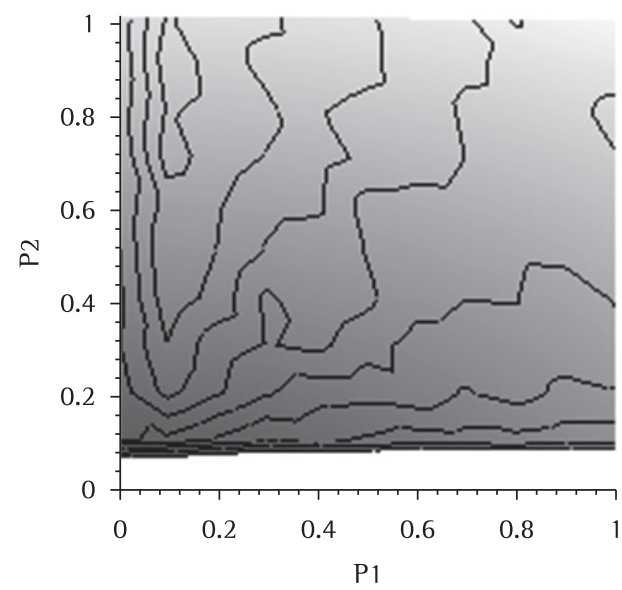

Figura 2. Conhecimento médio da organização após o equilíbrio, em função de $p_{1}$ e $p_{2}$. Fonte: elaborada pelos autores.

variando de 0,3 a 1 . Tal resultado é coerente com o postulado por March (1991), de que indivíduos que não se socializam com o código da empresa rapidamente contribuem mais para a possibilidade de exploration. Por outro lado, organizações pouco flexíveis (cujo código dificilmente se adapta às crenças dos indivíduos, neste caso representadas por $\mathrm{p}_{2}<0,2$ ), não conseguem atingir níveis altos de conhecimento, independente do tipo de indivíduos que delas façam parte.

Entretanto, nem sempre as empresas têm tempo suficiente para que o conhecimento atinja o ponto de equilíbrio. Na Figura 3, observa-se o percentual de aprendizagem gerado pelas variações de $p_{1}$ e $p_{2}$ após 10 períodos, na forma de uma superfície e de suas curvas de nível. Nessa condição transiente, o conhecimento maximal é adquirido com níveis de socialização com o código da organização $\left(p_{1}\right)$ ainda variando de 0,1 a 0,3, mas níveis de velocidade de aprendizagem organizacional $\left(\mathrm{p}_{2}\right)$ variando em uma 


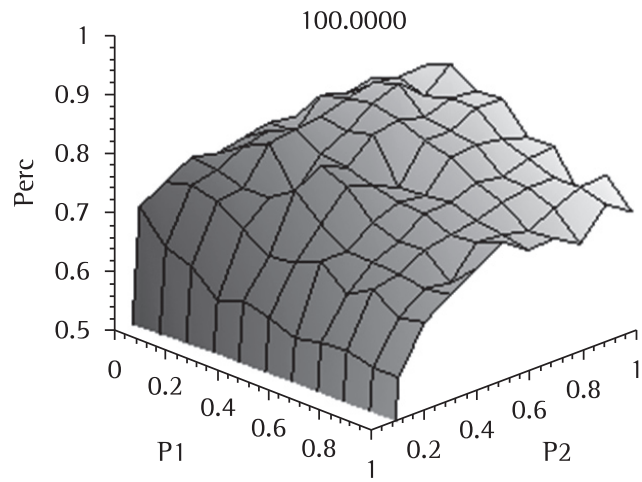

100.0000

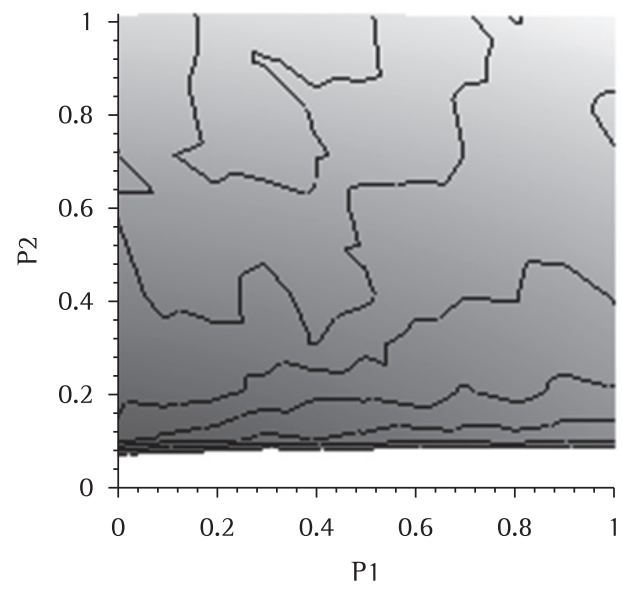

Figura 3. Conhecimento médio da organização após 10 períodos, em função de $p_{1}$ e $p_{2}$. Fonte: elaborada pelos autores.

faixa menor, de 0,6 a 1 . Ou seja, para períodos curtos ou de adaptação, a simulação indica uma combinação mais adequada em termos de ganho de conhecimento para organizações flexíveis (que aprendem rapidamente com os indivíduos), mas com indivíduos que não internalizam o código da organização de modo rápido. Aqui, novamente, organizações pouco flexíveis têm dificuldades em elevar o nível de conhecimento.

\subsection{Efeito da renovação de pessoal}

\section{(turnover) no conhecimento organizacional}

Considerando-se um sistema não fechado, ou seja, no qual fatores externos à organização fazem parte do modelo, diferentes desdobramentos poderão ser observados do ponto de vista da aprendizagem organizacional. 0 efeito da renovação de pessoal é apresentado no modelo de March (1991) por meio de uma probabilidade $\mathrm{p}_{3}$ de troca de cada indivíduo (turnover).
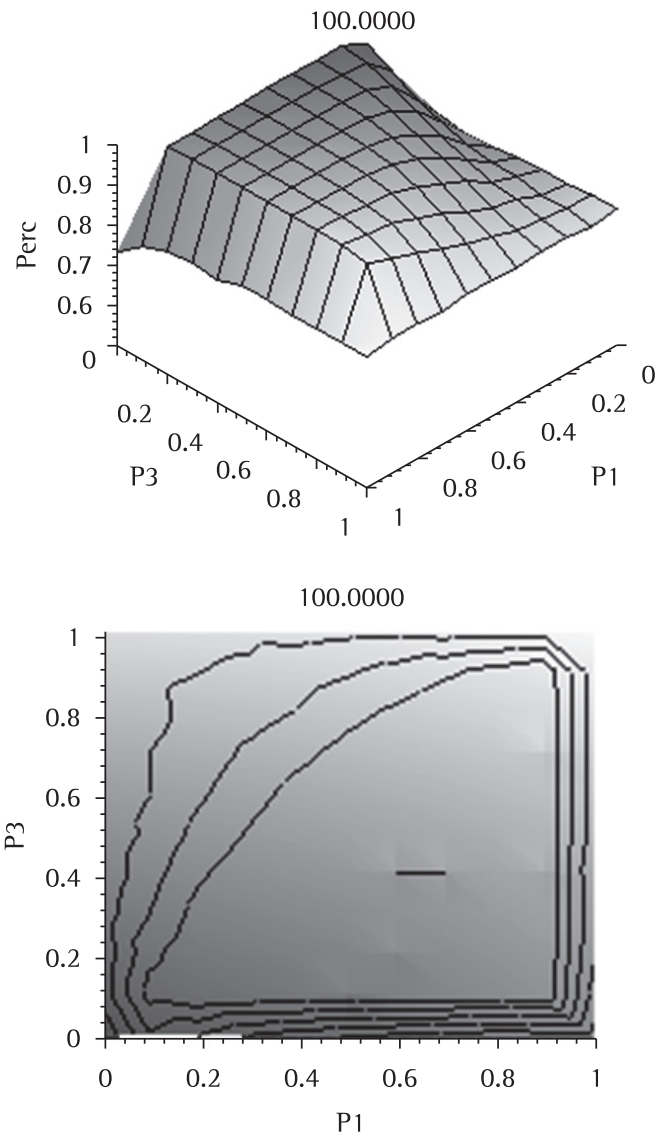

Figura 4. Conhecimento médio da organização após o equilíbrio em função de $p_{1}$ e $p_{3}\left(p_{2}=0,5\right)$. Fonte: elaborada pelos autores.

Inicialmente, a simulação permite observar que, não havendo um critério prévio no processo de seleção de pessoal, quanto ao conhecimento dos indivíduos, o máximo conhecimento para uma organização medianamente flexível $\left(p_{2}=0,5\right)$ ocorre em ambientes nos quais quanto maior o turnover $\left(\mathrm{p}_{3}\right)$, mais rapidamente os indivíduos aprendem (Figura 4). Pode-se inferir desse resultado que a aprendizagem rápida torna-se uma forma de garantir que o conhecimento já adquirido pelo código da organização não se perca com a troca de pessoal. Adicionalmente, quanto menor o turnover mantém-se a coerência com o resultado apresentado na seção anterior.

Considerando-se outros valores para o parâmetro $\mathrm{p}_{2}$ é possivel estudar os efeitos do turnover em relação à flexibilidade da organização para aprender. A Figura 5 apresenta a relação entre os parâmetros $p_{1}$ e $p_{3}$ para organizações com baixa $\left(p_{2}=0,1\right)$ e alta $\left(p_{2}=0,9\right)$ velocidade de aprendizagem organizacional. Observa-se que nas organizações pouco flexíveis, o conhecimento é maximizado 
100.0000

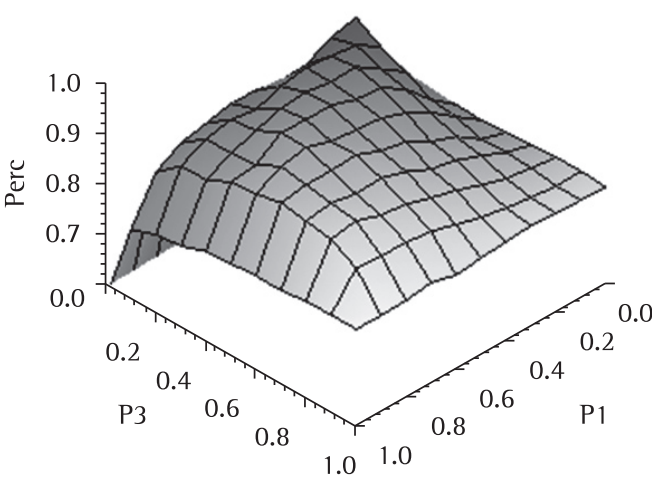

100.0000

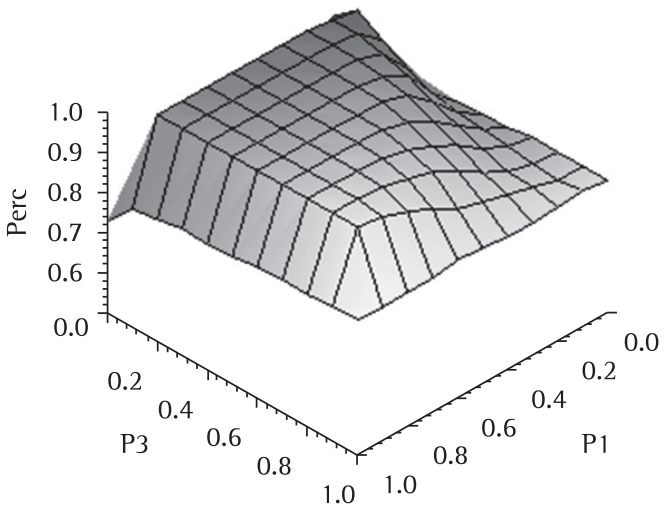

(a)

100.0000

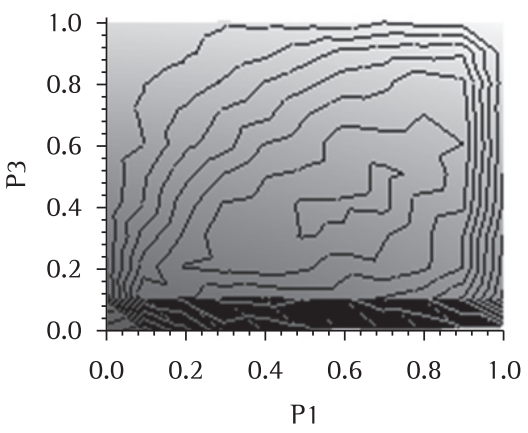

(b)

100.0000

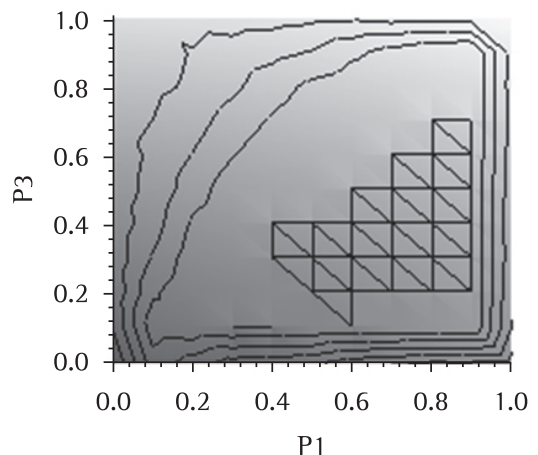

Figura 5. Conhecimento médio da organização após o equilíbrio em função de $p_{1}$ e $p_{3}$ em duas situações distintas: a) organizações pouco flexíveis $\left(\mathrm{p}_{2}=0,1\right)$; e b) organizações muito flexíveis $\left(\mathrm{p}_{2}=0,9\right)$. Fonte: elaborada pelos autores.

com taxas moderadas de turnover $(0,3$ a 0,5$)$ e com indivíduos que aprendem em velocidade mediana $(0,5$ a 0,7$)$. Por outro lado, em organizações altamente flexíveis, atinge-se o máximo de conhecimento em uma zona ampla na qual quanto maior o turnover, mais rápido os indivíduos devem aprender, situação semelhante à da empresa medianamente flexível. Observa-se que não há distinção perceptível entre os estados estacionários nos casos de organizações medianamente flexíveis $\left(p_{2}=0,5\right)$ e de organizações altamente flexíveis $\left(p_{2}=0,9\right)$. Essas análises ampliam a discussão proposta por March (1991) a partir do modelo original.

\section{Contribuições do modelo $\mathrm{SECl}$ ao modelo de aprendizagem mútua}

Nonaka e Takeuchi apresentam e refinam um modelo teórico de aprendizagem organizacional, conhecido como modelo SECl (NONAKA; TAKEUCHI,
1997; NONAKA, 2006; TAKEUCHI; NONAKA, 2008), que contempla as interações dos indivíduos entre si e destes com a organização. Nonaka e Takeuchi (1997) postulam quatro modos diferentes de conversão do conhecimento, tendo como pressuposto que o conhecimento é criado através da interação entre conhecimento tácito e explícito (Quadro 2). A Figura 6 apresenta a forma como esses quatro modos de conversão do conhecimento interagem.

Para Nonaka e Takeuchi (1997), o conhecimento tácito e o explícito não são entidades separadas, e sim complementares, interagindo um com o outro na medida em que os indivíduos realizam trocas criativas. Desta forma, a criação do conhecimento está ancorada tanto na interação social quanto nos conhecimentos tácitos e explícitos. E é por meio do processo de "conversão social" que esses conhecimentos se expandem, tanto em qualidade quanto em quantidade. Ainda para Nonaka e Takeuchi (1997), dentre os quatro modos de conversão do 
Quadro 2. Os modos de conversão de conhecimento.

\begin{tabular}{|c|l|l|}
\hline Socialização & Conversão de conhecimento tácito em conhecimento tácito; & Do indivíduo para o indivíduo. \\
\hline Externalização & Conversão de conhecimento tácito em conhecimento explícito; & Do indivíduo para o grupo. \\
\hline Combinação & Conversão de conhecimento explícito em conhecimento explícito; & Do grupo para a organização. \\
\hline Internalização & Conversão de conhecimento explícito em conhecimento tácito. & Da organização para o indivíduo. \\
\hline
\end{tabular}

Fonte: adaptado de Nonaka e Takeuchi (1997), e Takeuchi e Nonaka (2008).

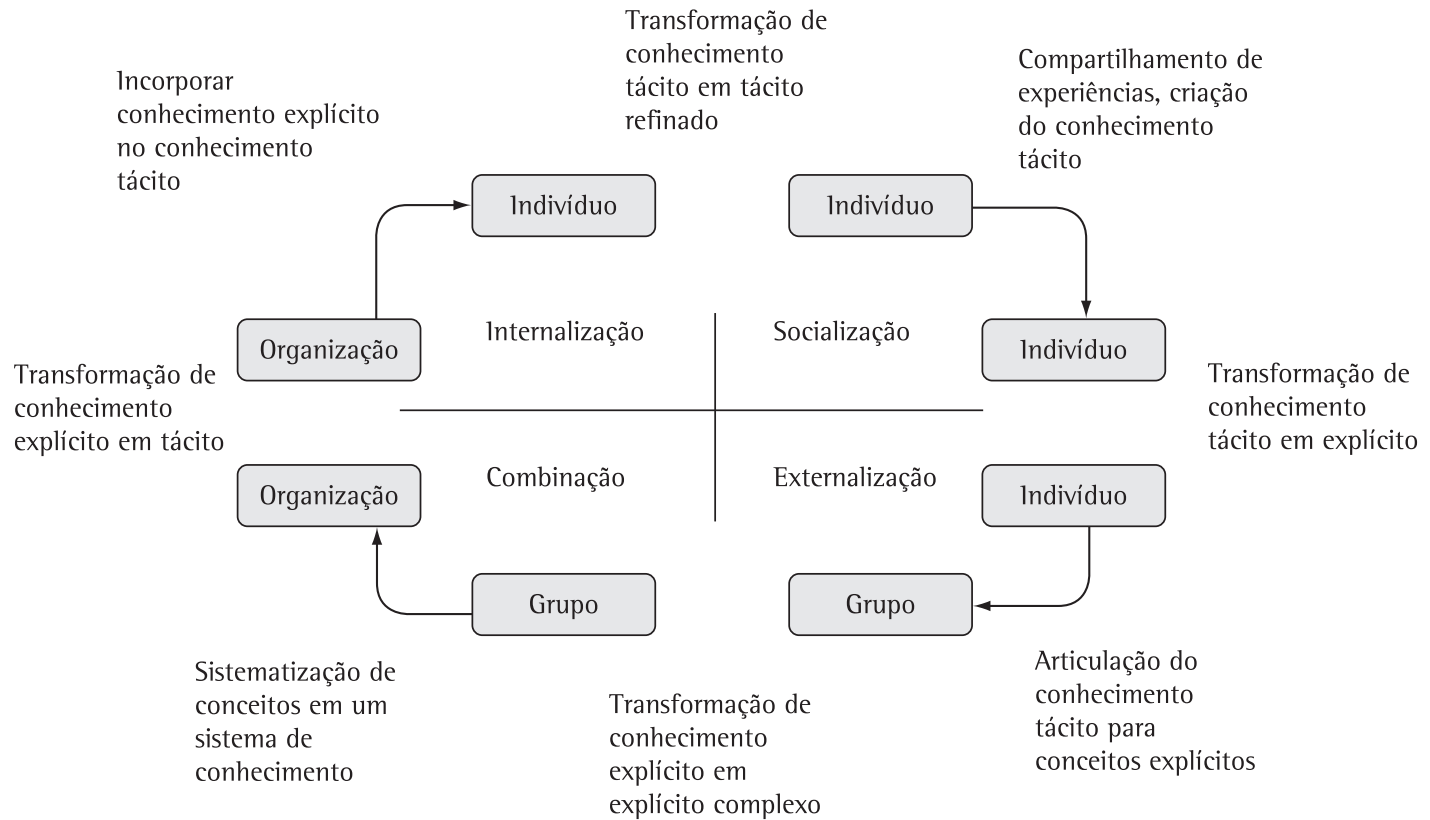

Figura 6. 0 modelo SECl de aprendizagem. Fonte: adaptado de Nonaka e Takeuchi (1997).

conhecimento, a externalização é a mais importante, sendo a chave para a criação do conhecimento, pois é o momento em que se criam novos conceitos explícitos a partir do conhecimento tácito.

A socialização é um processo de compartilhamento de experiências, ou seja, de conhecimento tácito entre indivíduos. Um indivíduo pode adquirir conhecimento tácito interagindo com outros, sem a necessidade do uso da linguagem (NONAKA; TAKEUCHI, 1997). Nonaka e Takeuchi (1997) e Riggins e Rhee (1998 apud FRANCINI, 2002) argumentam que a socialização ocorre quando indivíduos interagem uns com outros, por meio de observações de ações em uma relação do tipo “orientação". 0 aprendizado que ocorre no trabalho geralmente é criação de conhecimento por socialização. Nonaka e Takeuchi utilizam a metáfora de um aprendiz que aprende a arte de seu mestre não através da linguagem, mas apenas observando-o e praticando. Dessa forma, a base para aquisição de conhecimento tácito é a experiência. A possibilidade de os indivíduos aprenderem entre si é apontada não apenas por Nonaka e Takeuchi
(1997), mas está presente em outros modelos de aprendizagem organizacional. Crossan, Lane e White (1999), por exemplo, constroem um dos quatro processos de seu modelo a partir da interação entre os indivíduos:

\section{[...] Para que a coerência se desenvolva, é necessária a compreensão compartilhada pelos membros do grupo. E é por meio da contínua conversação entre os membros da comunidade e pelas práticas compartilhadas que se desenvolve a compreensão compartilhada [...] (CROSSAN; LANE; WHITE, 1999, p. 528).}

A externalização é um processo de articulação do conhecimento tácito em conceitos explícitos. Para tornar o conhecimento tácito em explícito, é comum fazer uso de metáforas, analogias, conceitos, modelos ou hipóteses. Emig (1983 apud NONAKA; TAKEUCHI, 1997) afirma que a escrita é a forma de converter o conhecimento tácito em conhecimento articulável, uma vez que, para conceituar uma imagem, a expressão usada é basicamente a da linguagem. Entretanto, a dificuldade de expressão dos indivíduos cria barreiras a essa articulação, tornando-a inadequada ou insuficiente. 
A sistematização de conceitos e do conhecimento é o que Nonaka e Takeuchi (1997) chamam de "combinação" - combinação de diferentes conjuntos de conhecimento explícito. Ela ocorre quando dados são manipulados por indivíduos (documentos, reuniões, e-mails etc.) e, então, reconfigurados em forma de relatórios (RIGGINS; RHEE, 1998 apud FRANCINI, 2002; NONAKA; TAKEUCHI, 1997). A combinação inclui a classificação e o acréscimo do conhecimento explícito, que pode levar à criação de novos conhecimentos (NONAKA; TAKEUCHI, 1997).

A internalização, o oposto da externalização, é o processo de transformação do conhecimento explícito em conhecimento tácito, ou seja, está intimamente relacionado com "aprender fazendo". As experiências, através da socialização, externalização e combinação, tornam-se ativos valiosos quando internalizadas nas bases do conhecimento tácito dos indivíduos sob a forma de know-how técnico ou como modelos mentais (NONAKA; TAKEUCHI, 1997).

Segundo Nonaka e Takeuchi (1997), esses processos de conversão de conhecimento interagem de forma contínua e dinâmica para criar novos conhecimentos, no que os autores chamam de espiral do conhecimento (Figura 7). Essa criação do conhecimento pode ser induzida por vários fatores. Para Nonaka e Takeuchi (1997), a socialização geralmente desenvolve um tipo de "campo" para as demais interações, facilitando o compartilhamento dos modelos mentais e experiências dos indivíduos. Já o diálogo ou reflexão coletiva é consequência da externalização, no qual se faz uso de metáforas ou analogias para transformar o conhecimento tácito, que de certa forma é difícil de ser comunicado. 0 modo combinação é provocado em seguida, quando se coloca o conhecimento recém-criado e o conhecimento já existente de outras áreas da empresa em uma rede, transformando esse conhecimento em novo serviço ou produto. Finalmente, aprender fazendo provoca a internalização.

Em outras palavras, a socialização gera 0 "conhecimento compartilhado", resultado de conversas informais. A externalização produz o "conhecimento conceitual", em que se expressam ideias através de metáforas. A combinação gera o "conhecimento sistêmico", resultando em novas tecnologias e protótipos. E, por fim, a internalização produz "conhecimento operacional" de processos de produção e uso de novas políticas (NONAKA; TAKEUCHI, 1997).

A abordagem do modelo $\mathrm{SECl}$ é semelhante à de March (1991) em dois aspectos essenciais:

- Considera tanto a aprendizagem individual quanto a coletiva;

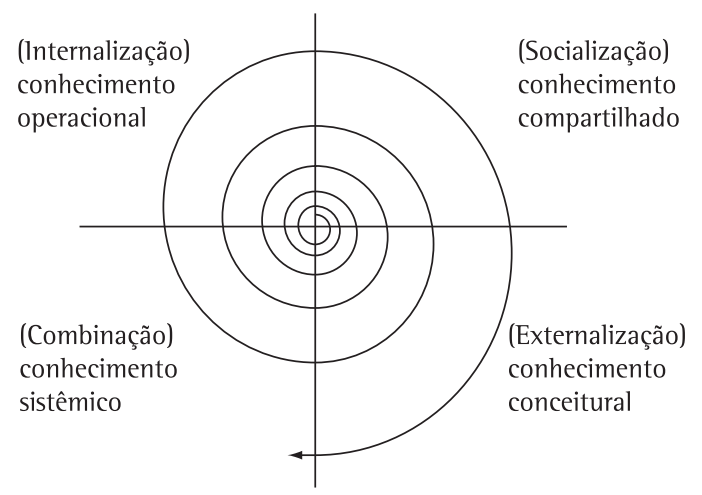

Figura 7. A espiral do conhecimento. Fonte: adaptado de Nonaka e Takeuchi (1997).

- Considera a interação como base do processo de aprendizagem.

Neste trabalho, considera-se que no modelo de aprendizagem mútua as dimensões de internalização (organização para indivíduo) e externalização (indivíduo para grupo) estão contempladas, respectivamente, por meio das probabilidades $\mathrm{p}_{1}$ e $\mathrm{p}_{2}$.

Ressalvas devem ser feitas para não haver erros de interpretação. Para o modelo de March (1991), a probabilidade $p$ representa a "socialização" do indivíduo com o código da organização, equivalendo à dimensão internalização do modelo $\mathrm{SECl}$, ou seja, a criação do conhecimento operacional. Nonaka e Takeuchi (1997), diferentemente, denominam como socialização a conversão de conhecimento tácito em tácito, de indivíduo para indivíduo.

Por outro lado, o modelo de aprendizagem mútua não considera as dimensões de socialização (indivíduo para indivíduo) e combinação (grupo para organização). Em razão disso, utilizou-se o modelo SECl como base para ampliar o modelo de March (1991), sendo feitos três acréscimos:

- Para ampliar a noção de internalização e analisar a questão relativa ao turnover e ao efeito que uma seleção de novos indivíduos que considere a aderência ao código da organização pode ter sobre o conhecimento adquirido, criou-se um parâmetro $p_{5}$ que representa o quanto as crenças dos novos indivíduos devem ser semelhantes às da organização para que eles ingressem nesta. Essa análise incorpora a possibilidade de retratar organizações com culturas "de devoção" (COLLINS; PORRAS, 1995), ou seja, organizações com ideologias rígidas que buscam contratar pessoas que compartilhem sua ideologia, seus valores e crenças. Harlow (2008) dá suporte a essa ideia - com base em um survey com 108 empresas, indica que o conhecimento tácito possui associação positiva com a capacidade de inovação (exploration) das organizações, mas a 
associação entre conhecimento tácito e resultados financeiros é relativamente mais fraca. A capacidade de criação de valor de um conhecimento depende de elementos como a aderência dos valores individuais aos da organização, alinhamento com a estratégia da organização e o potencial da constituição de redes de socialização (NONAKA, 2006). Apesar desse tópico não estar explicitado no modelo SECl, pode ser entendido como um fator que influencia fortemente os processos de internalização, pois aproxima os códigos dos indivíduos daqueles da organização. No modelo original, $p_{5}$ é igual a zero;

- Para representar a combinação (grupo para organização), criou-se a noção de influência do mercado na organização, já que um dos processos de combinação é coletar dados internos e externos à empresa e combinar esses dados (NONAKA; TAKEUCHI, 1997). Assim, criou-se primeiramente uma $m$-upla, que indica o conjunto de crenças a respeito da realidade compartilhado pelo mercado na qual a organização está inserida. Esse código assume valores $(-1,0,1)$, os quais têm iguais probabilidades de ocorrência, e as dimensões do código são independentes. Utilizou-se uma probabilidade $p_{6}$ de 0 código da organização ser afetado pela crença do mercado. No modelo original, $\mathrm{p}_{6}$ é igual a zero; e

- Para representar a socialização (indivíduo para indivíduo), criou-se a noção de zona de influência de cada indivíduo sobre os demais na organização. Como a transferência de conhecimento tácito requer proximidade física (NONAKA; TAKEUCHI, 1997), uma limitação da zona de influência se faz necessária. Assim assumiu-se que, em uma organização com $n$ indivíduos, cada indivíduo pode influenciar um percentual de indivíduos próximos. Nas simulações apresentadas neste artigo, a zona de influência foi estipulada em 10\% do total de indivíduos. 0 poder de influência é dado por $\mathrm{p}_{7}$, que representa a probabilidade de um indivíduo influenciar outro indivíduo próximo a ele. No modelo original, $p_{7}$ é igual a zero.
Acrescido desses parâmetros, o modelo proposto pode ser interpretado como um modelo de simulação computacional da espiral do conhecimento. 0 Quadro 3 apresenta uma comparação entre o modelo de March (1991), o modelo SECl de Nonaka e Takeuchi (1997) e o modelo proposto.

0 modelo proposto permite a análise de diferentes configurações de cenários, o que leva a variadas reflexões sobre aprendizagem organizacional e criação de conhecimento. Nonaka e Ryoko (2003) afirmam que o conhecimento e a capacidade de criar conhecimento são importantes para a sustentabilidade das vantagens competitivas, justificando a necessidade de entendimento do processo de aprendizagem organizacional. $\mathrm{Na}$ seção seguinte são discutidas algumas das análises possíveis a partir do modelo proposto.

\subsection{Efeito da aderência ao código da organização sobre o turnover}

Um conjunto de simulações foi realizado para analisar a geração de conhecimento na organização a partir da variação na taxa de turnover $\left(p_{3}\right)$ de 0 a 0,5 e em diferentes níveis de exigência quanto à aderência ao código da organização para novos contratados $\left(p_{5}\right)$. Para fins da simulação, considerou-se um cenário com indivíduos e organização medianamente flexíveis $\left(p_{1}=0,5\right.$ e $\left.p_{2}=0,5\right)$. A Figura 8 apresenta os resultados obtidos.

Pode-se observar que níveis baixos ou moderados de exigência da organização quanto a novos contratados $\left(p_{5}<0,5\right)$ não afetam 0 conhecimento adquirido. A partir desse nível, qualquer que seja a taxa de turnover, a organização perde capacidade de maximizar seu conhecimento. Ou seja, critérios de recrutamento e seleção que exijam uma aderência muito grande à ideologia e

Quadro 3. Comparação das características dos modelos de referência e do modelo proposto.

\begin{tabular}{|c|c|c|}
\hline Modelo SECl & Modelo de aprendizagem mútua & Modelo proposto \\
\hline Socialização & - & $\begin{array}{c}\text { Zona de influência } \\
\mathrm{p}_{7} \text {, poder de influência do indivíduo }\end{array}$ \\
\hline Externalização & $\mathrm{p}_{2}$, velocidade de aprendizagem organizacional & $p_{2}$, velocidade de aprendizagem organizacional \\
\hline \multirow[t]{2}{*}{ Combinação } & e & $\begin{array}{c}\text { Crença do mercado } \\
\mathrm{p}_{6} \text {, influência do mercado }\end{array}$ \\
\hline & $\mathrm{p}_{4}$, turbulência no ambiente & $\mathrm{p}_{4}$, turbulência no ambiente \\
\hline \multirow{2}{*}{ Internalização } & $\begin{array}{c}\mathrm{p}_{1} \text {, "socialização" do indivíduo com o código } \\
\text { da organização }\end{array}$ & $\begin{array}{c}\mathrm{p}_{1} \text {, "socialização" do indivíduo com o código } \\
\text { da organização }\end{array}$ \\
\hline & $\mathrm{p}_{3}$, turnover & $\begin{array}{c}\mathrm{p}_{3} \text {, turnover } \\
\mathrm{p}_{5} \text {, aderência ao código da organização }\end{array}$ \\
\hline
\end{tabular}

Fonte: elaborado pelos autores. 
100.0000

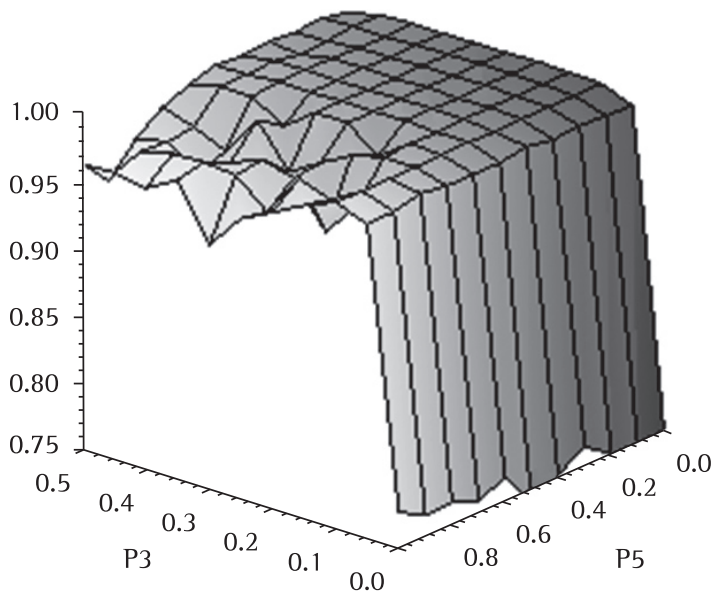

100.0000

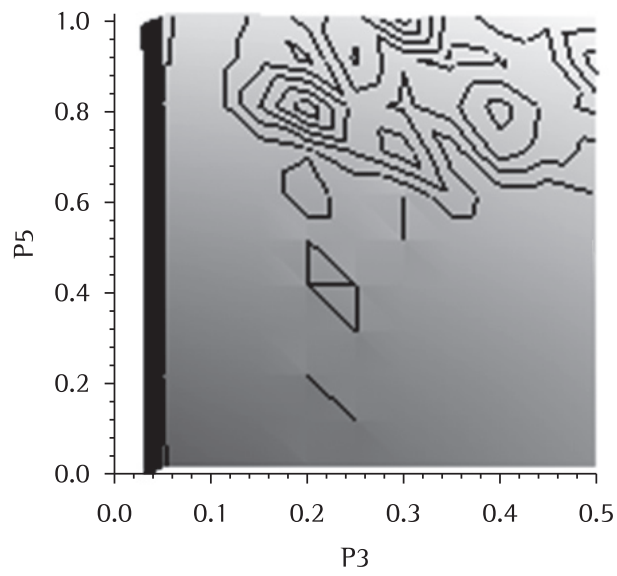

Figura 8. Conhecimento médio da organização após o equilíbrio em função de $p_{3}$ e $p_{5}\left(p_{1}=0,5\right.$ e $\left.p_{2}=0,5\right)$. Fonte: elaborada pelos autores.

às crenças da organização diminuem a possibilidade de exploration. Por outro lado, a presença de turnover $\left(\mathrm{p}_{3}>0,1\right)$, por estimular exploration, tende a gerar resultados de conhecimento melhores que os obtidos em um sistema fechado $\left(\mathrm{p}_{3}=0\right)$.

0 modelo proposto também permite analisar a relação do perfil de aprendizagem dos indivíduos $\left(p_{1}\right)$ com o nível de exigência de aderência ao código da organização $\left(p_{5}\right)$ em situações de substituição da força de trabalho. Foram consideradas empresas mediamente flexíveis $\left(p_{2}=0,5\right)$ a partir de situações de baixo e de alto turnover. A Figura 9 apresenta os resultados após o equilíbrio.

Observa-se que em situações de baixo turnover $\left(p_{3}=0,1\right)$ o conhecimento tende a ser maximizado por influência de indivíduos que não têm grande aderência inicial aos códigos da organização $\left(\mathrm{p}_{5}<0,6\right)$, mas que mediana ou rapidamente aprendem com ela $\left(0,5<p_{1}<0,9\right)$. Além disso, caso o nível de aderência ao código da organização na substituição seja alto $\left(p_{5}>0,8\right)$, torna-se mais difícil maximizar o conhecimento organizacional - apenas indivíduos medianamente flexíveis $\left(0,5<\mathrm{p}_{1}<0,7\right)$ contribuem para isso.

Por outro lado, em situações de alto turnover $\left(\mathrm{p}_{3}=0,5\right)$, a região maximal fica restrita a um nível entre baixo e mediano de exigência de aderência inicial aos códigos da organização $\left(p_{5}<0,5\right)$, mas com indivíduos que rapidamente se socializam com esse código $\left(0,6<p_{1}<0,9\right)$. Desse modo, equilibra-se a possibilidade de exploration (indivíduos pouco aderentes) e de exploitation (a rápida socialização mantém o conhecimento já adquirido pela organização).
Em ambos os casos, observa-se que um nível excessivamente elevado de aderência prévia ao código da organização tende a prejudicar a aprendizagem organizacional. Além disso, a simulação permite conjecturar que, mesmo que exista um nível alto de turnover na organização, ela pode maximizar seu conhecimento.

\subsection{Efeito da interação com o mercado no conhecimento da organização}

Os efeitos da turbulência no ambiente sobre o conhecimento organizacional foram estudados por March (1991) por meio da probabilidade $\left(\mathrm{p}_{4}\right)$ de que uma dimensão qualquer da realidade mude (de -1 para 1, ou de 1 para -1) em um determinado período de tempo. Essa seria uma forma de representar a ideia de que a compreensão da realidade pode ser dificultada pela turbulência no ambiente.

No modelo proposto, agrega-se a essa ideia a possibilidade de a organização ser influenciada pelas crenças do mercado. Como o conhecimento do mercado não é necessariamente maior que o da organização, e nem o mercado nem a organização conhecem diretamente a realidade, ao interagir com o mercado a organização pode diminuir seu conhecimento. Um conjunto de simulações foi realizado para avaliar o efeito da combinação como conversão de conhecimento. Os resultados de três cenários que analisam a relação do perfil de aprendizagem dos indivíduos $\left(p_{1}\right)$ com a velocidade de aprendizagem organizacional $\left(\mathrm{p}_{2}\right)$, considerando-se um estado transiente de 
100.0000

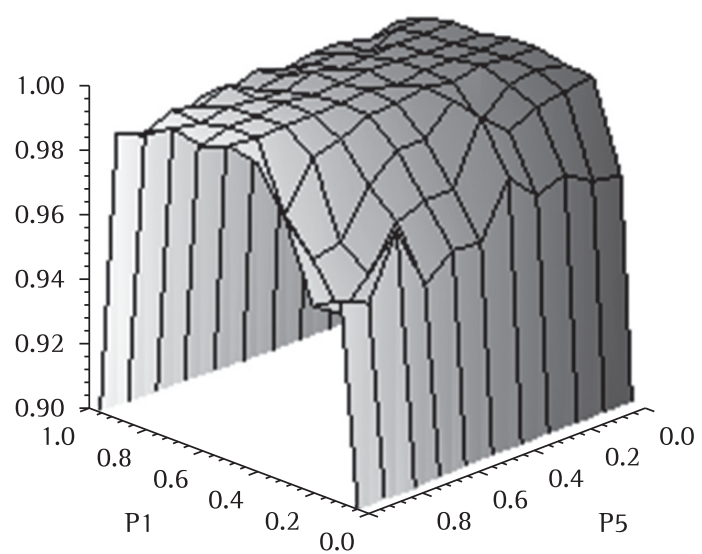

100.0000

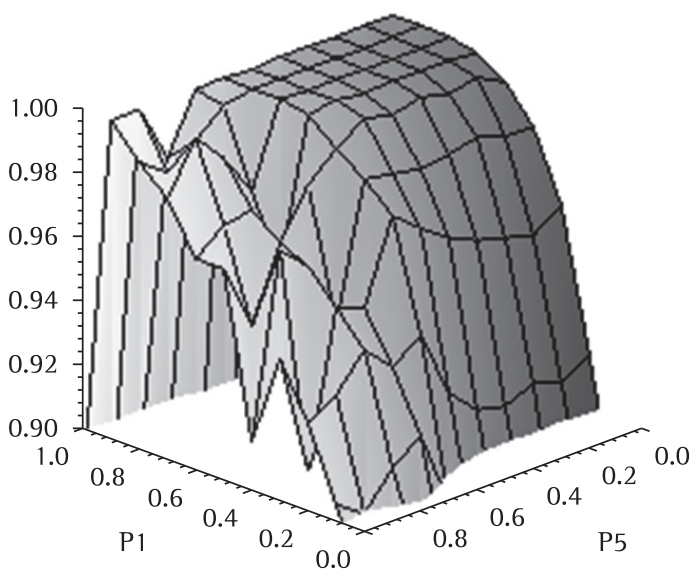

(a)

100.0000

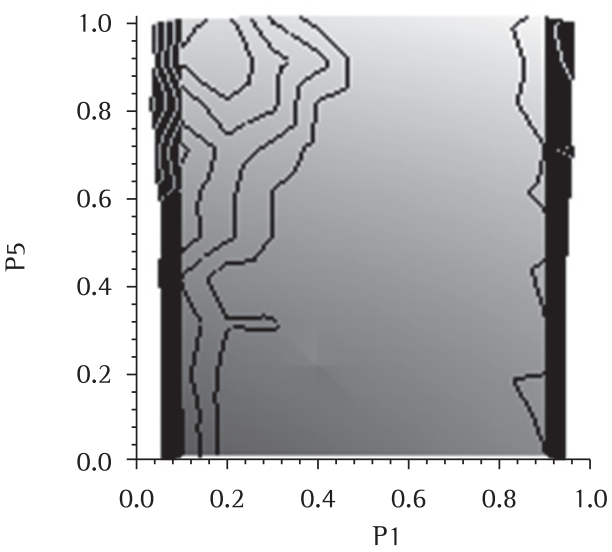

(b)

100.0000

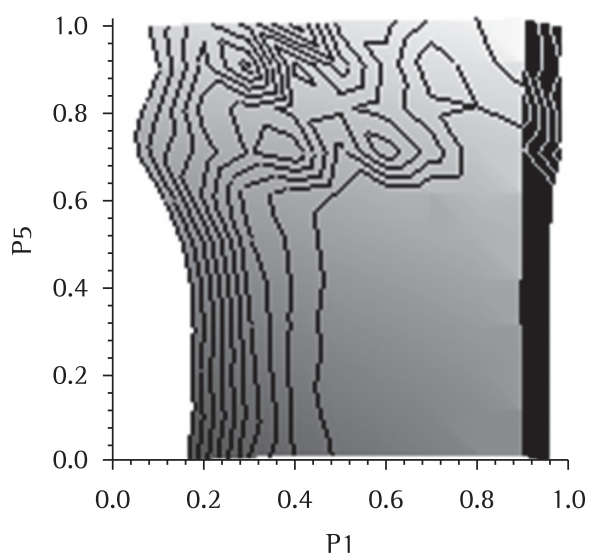

Figura 9. Conhecimento médio de uma organização medianamente flexível em termos de aprendizado organizacional $\left(p_{2}=0,5\right)$ após o equilíbrio em função de $p_{1}$ e $p_{5}$ em duas situações: a) baixo turnover $\left(p_{3}=0,1\right)$; e b) alto turnover $\left(p_{3}=0,5\right)$. Fonte: elaborada pelos autores.

20 períodos, e as mesmas condições iniciais da organização podem ser observadas na Figura 10, conforme segue:

- Figura 10(a): ambiente estável $\left(p_{4}=0\right)$ e interação mediana com o mercado $\left(\mathrm{p}_{6}=0,5\right)$;

- Figura 10(b): moderada turbulência no ambiente $\left(\mathrm{p}_{4}=0,1\right)$ e interação mediana com o mercado $\left(\mathrm{p}_{6}=0,5\right) ; \mathrm{e}$

- Figura 10(c): moderada turbulência no ambiente $\left(\mathrm{p}_{4}=0,1\right)$ e sem interação com o mercado $\left(\mathrm{p}_{6}=0\right)$.

Dos resultados observa-se que o conhecimento organizacional tende a ser maior quando há interação com o mercado em condições de estabilidade
(Figura 10a). Na presença de turbulência, ainda que moderada, o conhecimento organizacional é levado a patamares bem inferiores aos que ocorrem sem a turbulência quando considerada a interação com o mercado (Figura 10b). Por outro lado, em um ambiente de turbulência, a situação de não interação com o mercado mostrou-se superior em termos de geração de conhecimento organizacional (Figura 10c). Esse resultado pode indicar que, em situações de turbulência, o mercado pode influenciar negativamente a capacidade de adaptação (no sentido de aprendizagem) de uma organização.

Um cenário adicional foi avaliado em condições de turbulência moderada $\left(\mathrm{p}_{4}=0,1\right)$ e considerando indivíduos com velocidade mediana de socialização com o código da organização $\left(p_{1}=0,5\right)$. Nesse 

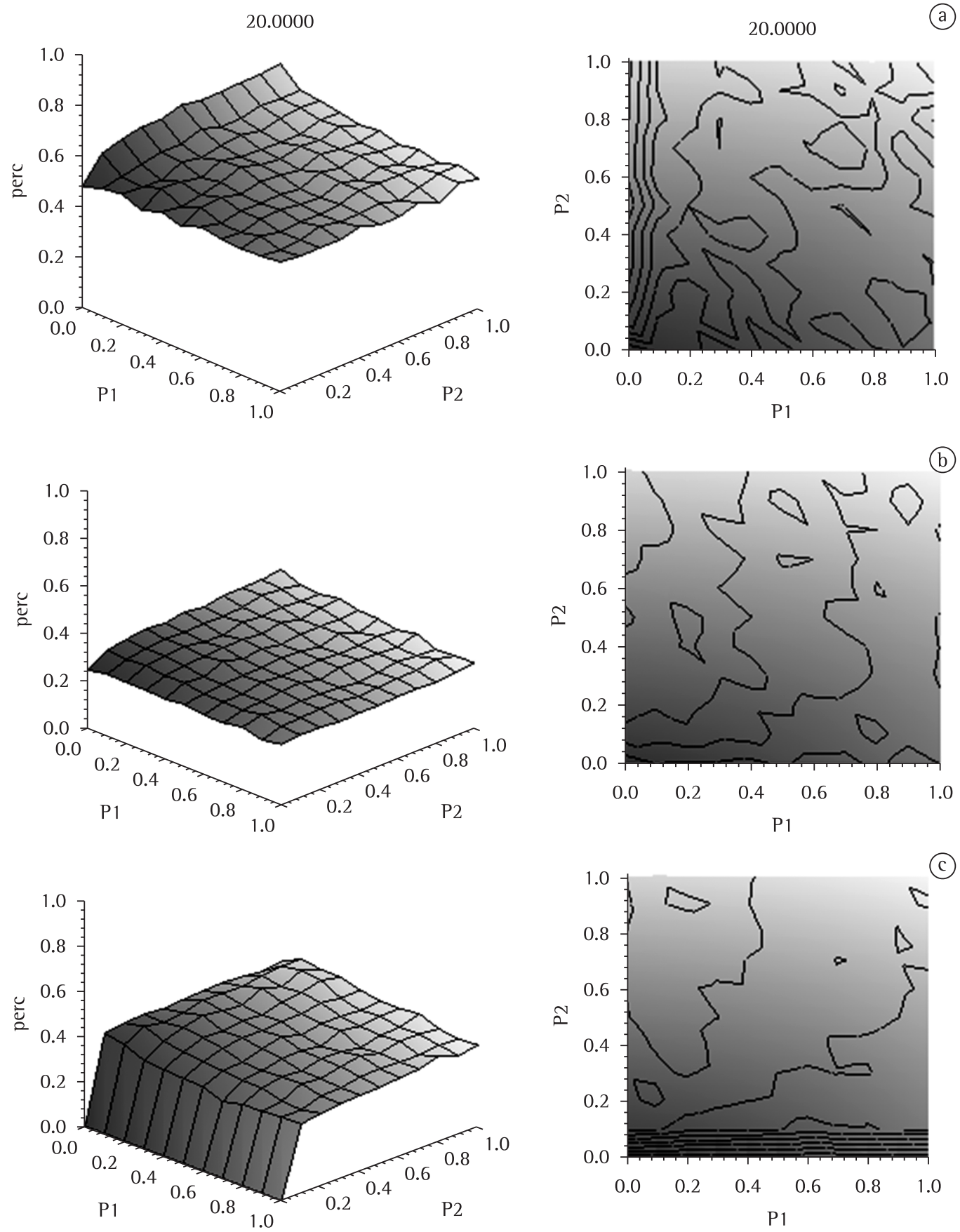

Figura 10. Conhecimento médio da organização após 20 períodos em função de $p_{1}$ e $p_{2}$. a) $p_{4}=0$ e $\left.p_{6}=0,5 ; b\right) p_{4}=0,1$ e $p_{6}=0,5$; e c) $p_{4}=0,1$ e $p_{6}=0$. Fonte: elaborada pelos autores.

caso, foram relacionadas diferentes velocidades de aprendizagem organizacional $\left(p_{2}\right)$ e variadas taxas de aprendizagem com o mercado $\left(\mathrm{p}_{\mathrm{f}}\right)$. A Figura 11 apresenta os resultados encontrados. Percebe-se que quanto mais o mercado influencia uma organização, menor é o conhecimento atingido por ela.

\subsection{Efeito da aprendizagem entre os} indivíduos no conhecimento da organização

Um conjunto de cenários foi gerado para avaliar a influência da socialização (no sentido de Nonaka e Takeuchi, 1997) em relação aos 
diferentes perfis de aprendizagem dos indivíduos. A Figura 12 mostra os resultados gerados em termos de conhecimento organizacional após o equilíbrio. Observa-se que a organização tende a ganhar com taxas baixas de influência entre indivíduos $\left(0<p_{7}<0,4\right)$, na medida em que eles tenham baixa velocidade de socialização com o código da organização $(0,1<\mathrm{p}<0,4)$ - essa seria uma forma de maximizar as possibilidades de exploration. Pode-se conjecturar que na medida em que aumenta a adaptabilidade dos indivíduos ao código da organização, mais a socialização entre indivíduos será benéfica, até o limite anteriormente estabelecido.

Comparando o resultado da Figura 13, que considera uma interação moderada entre os indivíduos, com a Figura 14, em que não há aprendizagem por socialização, observa-se que para quaisquer $p_{1}$ e $p_{2}$ a organização ganha em conhecimento ao ter uma interação de aprendizagem moderada entre seus membros.

Outra diferença relevante ao se considerar a possibilidade de um indivíduo aprender com outro é que a região de conhecimento maximal se desloca consideravelmente. Considerando o cenário sem socialização da Figura 14, em que os indivíduos aprendemapenas coma organização, o conhecimento máximo se dá para organizações altamente flexíveis e indivíduos que não se socializam com o código da organização rapidamente - o que maximizaria a possibilidade de exploration. Por outro lado, em um cenário em que os indivíduos aprendem uns com os outros, o máximo conhecimento se dá para organizações com flexibilidade de moderada
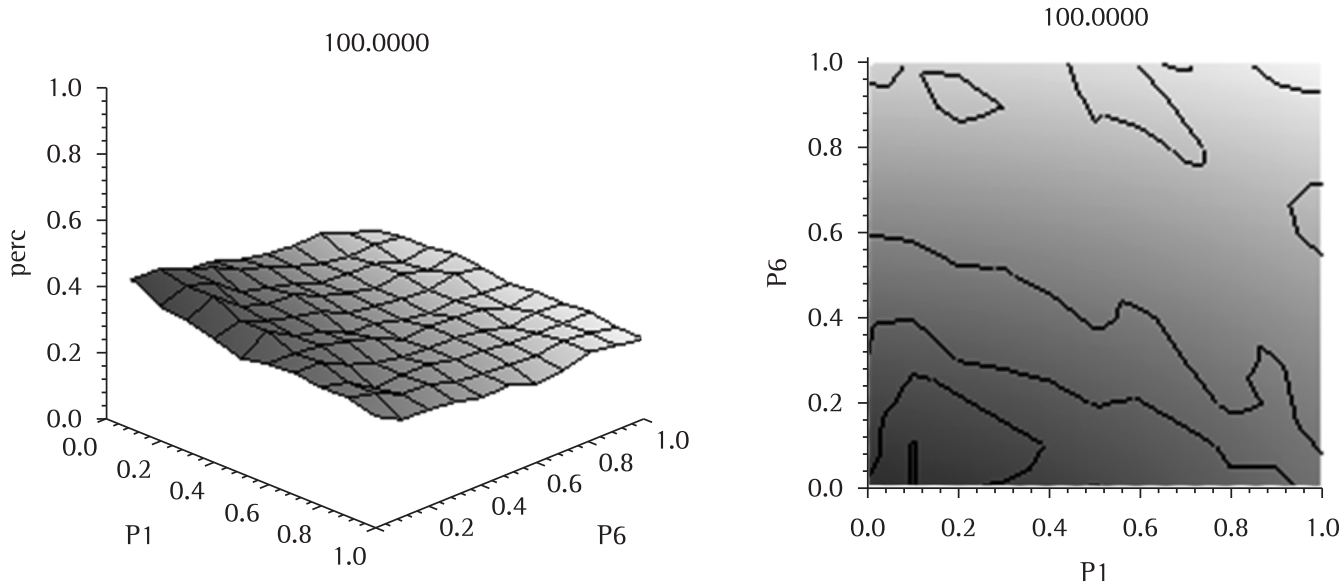

Figura 11. Conhecimento médio da organização após 20 períodos em função de $p_{2}$ e $p_{0}\left(p_{4}=0,1\right.$ e $\left.p_{1}=0,5\right)$. Fonte: elaborada pelos autores.
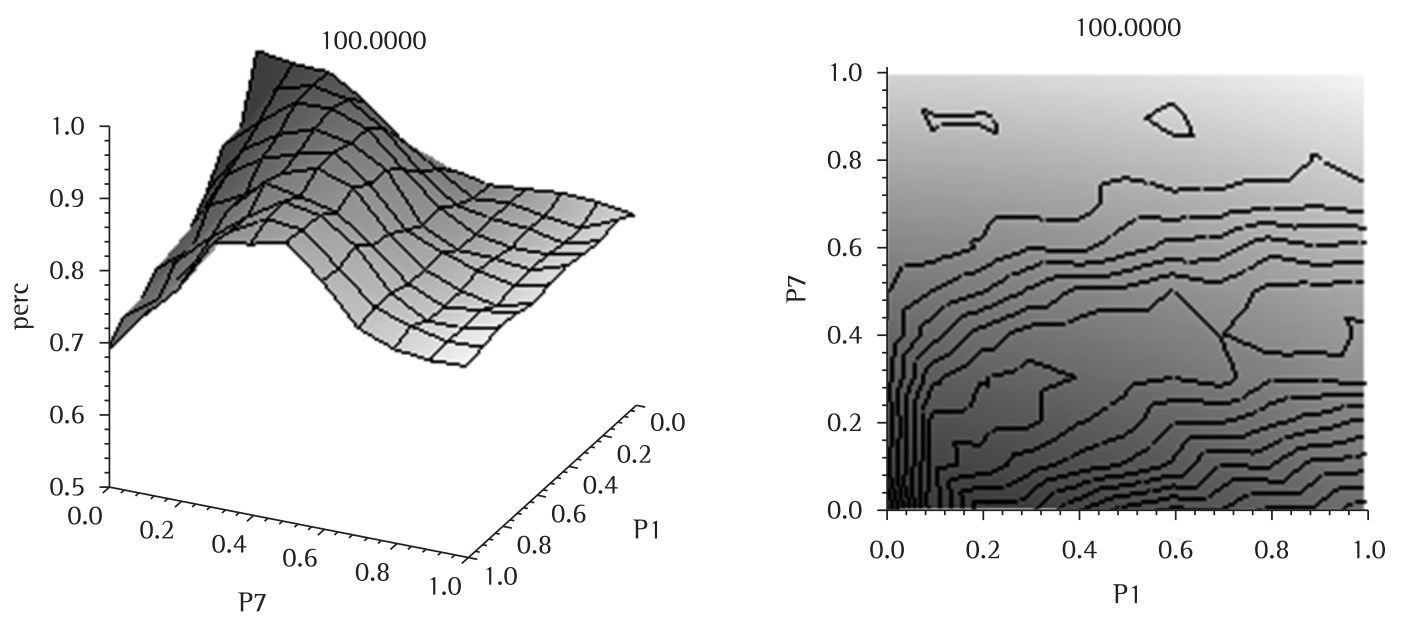

Figura 12. Conhecimento médio da organização após o equilíbrio em função de $p_{1}$ e $p_{7}\left(p_{2}=0,5\right)$. Fonte: elaborada pelos autores. 
100.0000

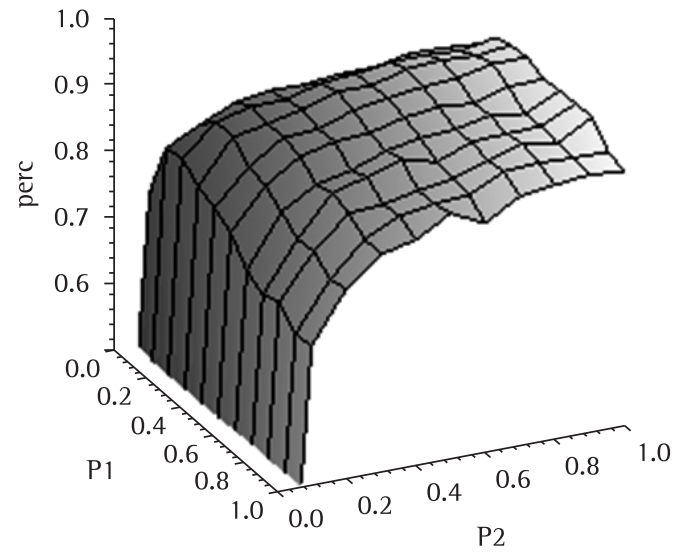

100.0000

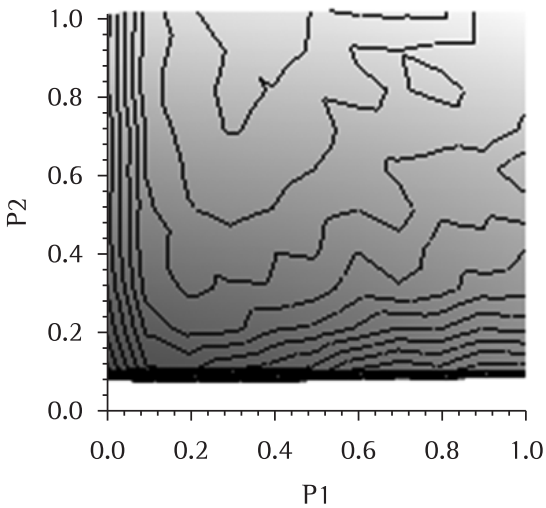

Figura 13. Conhecimento médio da organização após o equilíbrio em função de $p_{1}$ e $p_{2}\left(p_{7}=0,3\right)$. Fonte: elaborada pelos autores.

100.0000

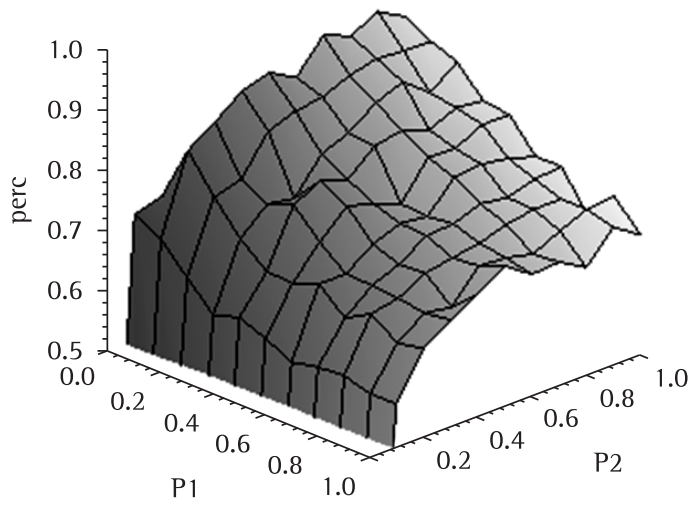

100.0000

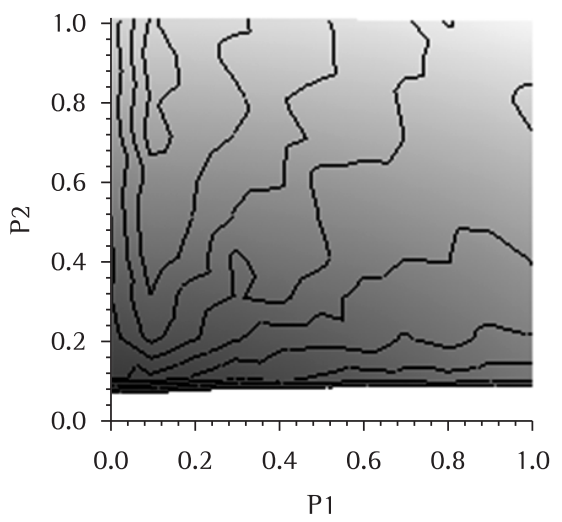

Figura 14. Conhecimento médio da organização após o equilíbrio, em função de de $p_{1}$ e $p_{2}\left(p_{7}=0\right)$. Fonte: elaborada pelos autores.

a alta, e indivíduos com variadas velocidades de socialização. Pode-se inferir que nessa situação haveria um equilíbrio dinâmico entre exploration e exploitation. Assim, o estudo de simulação levanta a conjectura de que uma organização altamente flexível pode se beneficiar de indivíduos com as mais variadas taxas de socialização com o código e que possam interagir entre si.

\section{Análise e discussão}

0 estudo de simulação realizado sobre o modelo proposto permite estabelecer diversas conjecturas sobre 0 relacionamento entre aprendizagem organizacional e criação de conhecimento. Ao identificar diferentes condições organizacionais e potenciais de geração de conhecimento em cada situação, pode-se estabelecer novas conjecturas sobre a geração de valor a partir da geração de conhecimento organizacional. A incorporação dos referenciais do modelo $\mathrm{SECl}$ ao modelo de aprendizagem mútua permite explorar as dimensões de socialização e combinação, antes não disponíveis. Assim, novas perspectivas sobre a dinâmica entre exploration e exploitation podem ser exploradas.

Edvinsson e Malone (1997 apud FRANCINI, 2002) propõem que a soma de capital humano e capital estrutural resulta em capital intelectual. Como tipicamente não há como medir o capital intelectual (ou o potencial de aprendizagem organizacional), organizações financeiramente atrativas para investimento podem não o ser do ponto de vista de sustentabilidade e geração de conhecimento. Por outro lado, Nonaka e Takeuchi (1997) e Harlow (2008) afirmam que companhias que possuem capacidade de transformar 0 conhecimento são empresas propensas ao sucesso, uma vez que o intelecto cria valor agregado. 
Esse valor agregado pode reverter-se em ganhos sustentáveis, promovendo alinhamento às tendências mercadológicas e vantagens competitivas. Organizações que conseguem administrar a criação do conhecimento, consequentemente, têm maior possibilidade de agregar valor aos produtos e serviços, seja em inovação (exploration) ou melhorias (exploitation).

A análise mostra que, havendo disponibilidade de informação e autoconhecimento, por parte da organização, em termos de seu grau de flexibilidade e da flexibilidade dos indivíduos que a compõem, é possível estabelecer uma avaliação do potencial de geração de conhecimento organizacional. Além disso, pela comparação propiciada pelo modelo de simulação, é possivel estabelecer estratégias que levem à geração de conhecimento sustentável ao longo do tempo.

A dimensão de aprendizagem com o mercado pode ser estudada à luz da teoria institucional. As implicações da aprendizagem com o mercado, especialmente em ambientes turbulentos, podem ajudar na compreensão do isomorfismo mimético e dos mitos racionalizados incorporados em algumas práticas adotadas compulsoriamente por organizações dentro de determinadas indústrias e que acabam se revelando pouco sustentáveis ao longo do tempo.

0 modelo proposto agrega ao referencial uma possibilidade de quantificar, em caráter exploratório, o potencial de aprendizagem de um dado perfil de organização. Provê indícios, também, de que não há um perfil típico de organização de aprendizagem, mas um campo de decisões associado à estratégia das organizações, no qual o conhecimento organizacional é mais um elemento de criação de valor disponível para a gestão. Dessa forma, a análise dos diversos resultados dos experimentos de simulação realizados com o modelo proposto permite destacar alguns pontos para análise futura bem como possíveis orientações de cunho prático aos gestores.

\section{Considerações finais}

Parece ficar evidente a necessidade de a organização "conhecer a si mesma". Qualquer que seja a sua cultura ou seu nível de flexibilidade, se tais dimensões forem conhecidas, pode-se direcionar a gestão das pessoas e da aprendizagem para maximizar o conhecimento organizacional. Assim, ao invés de um modelo ideal de organização a ser copiado (organização de aprendizagem), seja ele o de uma organização flexível ou o de uma organização de cultura, valores e normas extremamente sólidos (como as organizações visionárias), o que se apresenta são modos diversos de gestão, que partem do conhecimento da organização e de sua cultura e buscam, a partir disso, maximizar resultados em termos de aprendizagem organizacional.

Ampliar o estudo dos processos de aprendizagem em organizações a partir das teorias já desenvolvidas, agregando a elas o estudo de cenários variados, pode contribuir enormemente para uma compreensão maior na área, que oriente para a definição de possíveis indicadores e medidas e sirva de base para trabalhos empíricos que possam ser mais do que textos prescritivos. 0 uso de simulação computacional permite impor hipóteses sobre as dimensões e as regras tecnológicas a serem testadas, favorecendo a avaliação de cenários alternativos e a obtenção de insights sobre o comportamento de diferentes ambientes. Com base nesses insights, o pesquisador poderá buscar evidências empíricas e comparar os resultados de casos de aplicação, confrontando seus pressupostos com evidências reais e refinando sua percepção do mundo, mesmo em contextos abstratos e de amplo escopo, como o da aprendizagem organizacional.

\section{Referências}

CASSEL, G. L.; VACCARO, G. L. R. $A$ Aplicação de simulação-otimização para a definição do mix ótimo de produção de uma indústria metal-mecânica. In: ENCONTRO NACIONAL DE ENGENHARIA DE PRODUÇÃO, 27., 2007, Foz do lguaçu. Anais... Foz do lguaçu: ABEPRO, 2007.

COHEN, W. M.; LEVINTHAL, D. A. Absorptive capacity: a new perspective on learning and innovation. Administrative Science Quaterly, v. 35, n.1, p. 128-152, 1990.

COLlINS, J.; PORRAS, J. Feitas para durar: práticas bem-sucedidas de empresas visionárias. Rio de Janeiro: Rocco, 1995.

CROSSAN, M.; LANE, H. W.; WHITE, R. E. An organizational learning framework: from intuition to institution. Academy of Management. The Academy of Management Review, v. 24, n. 3; p. 522-537, 1999.

FlOL, C. M.; LYLES, M. A. Organizational learning. Academy of Management. The Academy of Management Review, v. 10, n. 4 , p. $803-813,1985$.

FLEURY, A. C. C.; FLEURY, M. T. L. Estratégias empresariais e formação de competências: um quebra-cabeça caleidoscópico da indústria brasileira. 3. ed. São Paulo: Atlas, 2004.

FRANCINI, W. S. A gestão do conhecimento: conectando estratégia e valor para a empresa. RAE-eletrônica, v. 1, n. 2, 2002.

GARVIN, D. A. The processes of organization and management. Sloan Management Review, v. 39, n. 4, p. 33-50, 1998.

HARLOW, $H$. The effect of tacit knowledge on firm performance. Journal of Knowledge Management, v. 12, n. 1, p. 148-163, 2008. 
LAHTEENMAKl, S.; TOIVONEN, J.; MATTILA, M. Critical aspects of organizational learning research and proposals for its measurement. British Journal of Management, v. 12, p. 113-129, 2001.

MARCH, J. Exploration and exploitationin organizational learning. In: COHEN, M.; SPROULL, L. Organizational learning. Califórnia: Sage, 1991.

NADLER, D.; GERSTEIN, M. S.; SHAW, R. B. Arquitetura organizacional: a chave para a mudança empresarial. Rio de Janeiro: Campus, 1992.

NONAKA, 1. A empresa criadora de conhecimento. Aprendizagem organizacional: os melhores artigos da Harvard Business Review. Rio de Janeiro: Elsevier, 2006.

NONAKA, 1; RYOKO, T. The knowledge-creating theory revisited: knowledge creation as a synthesizing process. Knowledge Management Research \& Practice, n. 1, p. 2-10, 2003.

NONAKA, 1.; TAKEUCHI, H. Criação de conhecimento na empresa. Rio de Janeiro: Campus, 1997.

PIDD, M. Modelagem empresarial: ferramentas para a tomada de decisão. Porto Alegre: Artes Médicas, 1994.

SANCHEZ, R.; HEENE, A. A Competence perspective on strategic learning and knowledge management. In:
SANCHEZ, R.; HEENE, A. (Eds.). Strategic learning and knowledge management. Chichester: John Wiley \& Sons, 1997. p. 3-15.

SHANNON, R. E. Introdution to simulation. In: WINTER SIMULATION CONFERENCE, 24., 1992, San Diego. Proceedings... San Diego: ASA, 1992. p. 65-73.

SHRIVASTAVA, P. A typology of organizational learning systems. Journal of Management Studies, v. 20, n. 1, 1983.

SOUZA, Y. S. Organizações de aprendizagem ou aprendizagem organizacional. RAE-eletrônica, v. 3, n. 1, 2004.

TAKEUCHI,H; NONAKA, I. Gestão do conhecimento. Porto Alegre: Bookman, 2008.

VACCARO, G. L. R. Modelagem e análise de dados em simulação. Porto Alegre: Instituto de. Informática/ UFRGS, 1999. Projeto de doutorado.

ZANGISKl, M. A. S. G.; LIMA, E. P.; COSTA, S. E. G. Aprendizagem organizacional e desenvolvimento de competências: uma síntese a partir da gestão do conhecimento. Produto \& Produção, vol. 10, n. 1, p. 54-74, 2009.

\title{
A computer simulation study for the analysis of profiles of organizational learning
}

\begin{abstract}
This paper presents a computer simulation model that extends the model of Mutual Learning proposed by March (1991) based on the SECl model presented by Nonaka and Takeuchi (1997). Initially some considerations are presented on organizational learning and the model itself. Then the model proposed by March is revisited, and extensions are proposed. Various scenarios of evolution of the model are simulated, and the proposed extensions are analyzed. The results are analyzed, based on the theoretical framework proposed. Finally, some considerations are presented on the interpretation of results obtained in different organizational environments, in order to discuss the relationship between profiles of organizations and organizational learning.
\end{abstract}

Keywords

Simulation. Organizational learning. Learning models. 